\title{
Carcinoid Tumour of the Appendix: An Analysis of 1,485 Consecutive Emergency Appendectomies
}

\author{
K. H. in't Hof • H. C. van der Wal • \\ G. Kazemier • J. F. Lange
}

Received: 31 January 2008 / Accepted: 2 May 2008 /Published online: 3 June 2008

(C) 2008 The Author(s)

\begin{abstract} of the appendix in emergency appendectomies. with the literature. appendix is good.

Keywords Acute appendicitis · Carcinoid tumour

\section{Introduction}

Carcinoid tumour of the appendix is one of the most common single presentations of this type of tumour and is thereby the most common type of primary malignant lesions of the appendix. ${ }^{1}$ The ileum is the second common site of presentation. ${ }^{1}$ The carcinoid tumours of the appendix are often asymptomatic and found by chance during appendectomy or other abdominal operations. Carcinoid tumours are found in $0.3-0.9 \%$ of patients undergoing
\end{abstract}

Aim The aim of this study is to conduct a retrospective analysis of the incidence and long-term results of carcinoid tumours

Methods A retrospective review of 1,485 appendectomies was performed in two centres from January 2000 until January 2006. Demographic data, clinical presentation, histopathology, operative reports and survival were scored and compared

Results In three women and four men, carcinoid tumours were identified (0.47\%). The mean age was 32.7 years (range, 20 59 years). The clinical presentation was resembling the symptoms of acute appendicitis in all cases. Laparoscopic appendectomy was the treatment of choice in five patients; in one of these patients, a conversion to laparotomy was necessary. The other two patients underwent primary open appendectomy. Five patients underwent additional surgery after the pathology report became available. Four patients underwent ileocecal resection; one other patient underwent right hemicolectomy. In none of the re-operation specimens was residual carcinoid tumour detected. After a mean follow-up of 65 months (range, 25-92), all patients were alive and disease- and symptom-free.

Conclusion Carcinoid tumours of the appendix most often present as acute appendicitis. It also emphasises the value of histopathological analysis of every removed appendix. The long-term prognosis of incidentally found carcinoids of the

K. H. in't Hof $(\bowtie) \cdot$ H. C. van der Wal $\cdot$ G. Kazemier $\cdot$ J. F. Lange

Department of surgery, Erasmus Medical Centre,

Rotterdam, The Netherlands

e-mail: k.inthof@erasmusmc.nl appendectomy. ${ }^{1,2}$ Tumour characteristics predict the behaviour of the tumour. ${ }^{2,3}$ The majority of patients with a incidental carcinoid are cured by appendectomy. The recommendations in literature for adjuvant surgery are irradical resection margins, tumour size greater than $2 \mathrm{~cm}$ and goblet-type carcinoid. ${ }^{4}$ Most surgeons will encounter this clinical problem only once in a lifetime. For this reason, in our opinion, even a small database will be a useful aid for the management of primary carcinoid tumours of the appendix. In this study, we aim for retrospective analysis of the incidence and long results of carcinoid tumours of the appendix in emergency appendectomies.

\section{Materials and Methods}

The study is a retrospective analysis of patients undergoing appendectomies performed between January 2000 till 
January 2006 in the Erasmus University Medical Centre (Erasmus MC) and the Medical Centre Rijnmond Zuid (MCRZ), a Rotterdam community teaching hospital. Data were reviewed on demography, clinical presentation, histopathology, operative reports and long-term outcomes. The used definition of acute appendicitis was granulocyte infiltration through all layers of the appendiceal wall. The follow-up contained medical history, blood samples and octreotide imaging or computed tomography scan. Outpatient clinical controls were at least twice a year.

\section{Results}

In the study period, 1,485 patients underwent a laparoscopic or open appendectomy for suspected acute appendicitis. The histopathology of seven patients showed carcinoid tumour. All specimen of those seven patients showed acute appendicitis as well. Of those seven patients, four were men and three were women. They had a mean age of 32.7 years (range, 20-59 years). In five patients, laparoscopic appendectomy was performed; in one of these patients, conversion was necessary because of anatomical reasons. Two patients underwent primary open appendectomy, one because of technical reasons and the other patients because of a ventriculoperitoneal drain. In six patients, the diagnosis was carcinoid; in one patient the histopathology showed a goblet type carcinoid. In four patients, the tumour was located at the tip of the appendix. In two cases, the tumour was located at the base and in one in the body of the appendix. In two patients, tumour diameter was greater than $2 \mathrm{~cm}$, and in one of these, a micro-metastasis was found in the mesentery of the appendix. Two other patients had positive resection margins at the base of the appendix. Four of these patients underwent ileocecal resection, two laparoscopic and two open. One patient underwent laparoscopic right hemicolectomy. In none of the re-operation specimens, residual tumour activity was observed, and no lymph node involvement was seen. Mean lymph node harvest was 11 (range, 5-17). In the other two patients who underwent appendectomy and a tumour less than $1 \mathrm{~cm}$, no reintervention was performed. All patients have remained tumour-free during a mean follow-up of 65 month (range, 25-92 months).

\section{Discussion}

The prevalence of carcinoid tumour in patients undergoing emergency appendectomy is in our database $0.47 \%$. The literature describes percentages between $0.3-0.9 \%$ and a little dominant occurrence in female patients. ${ }^{1,2,5-8}$ Unusual is the predominance of male patients in our series-four to three - probably due to the small series. The mean age of presentation at 32 years is lower than in large epidemiological studies, suggesting an average diagnostic age between 38 and 49 years, even higher for the goblet-type carcinoid tumour (52 versus 42 years), also possibly related to these small numbers. ${ }^{7,8}$ All seven patients presented with acute appendicitis. Probably by the absence of liver metastasis, also in retrospection, no signs of carcinoid tumour could be detected. During appendectomy, in none of the patients, the suspicion of appendicular tumour was raised. In all cases, histopathology reflected an inflammatory response adjacent to the tumour. This pleas for routine pathology of all removed appendices in patients with macroscopically inflamed appendices. In four patients, the tumour was located at the tip of the appendix: in two cases at the base and in one in the body of the appendix. This is in accordance with the literature. ${ }^{6,9}$ Carcinoid tumours of the appendix rarely metastasise. ${ }^{2,3,5}$ Sporadically extended metastasis disease of a carcinoid tumour of the appendix is described. ${ }^{3}$ In a review, Goede et al. describe that acceptable indications for re-intervention represented by all lesions larger than $2 \mathrm{~cm}$ in diameter, histological evidence of mesoappendiceal extension, tumours at the base of the appendix with positive margins or involvement of the cecum, high-grade malignant carcinoids and gobletcell adenocarcinoids. ${ }^{4}$ The recommended resection is represented by right hemicolectomy. The consensus that appendiceal carcinoid tumours with a size smaller than $2 \mathrm{~cm}$ after radical resection need no further treatment because of minimal metastatic behaviour was followed successfully in this series. In two patients with a tumour at the base of the appendix and a tumour size smaller than $2 \mathrm{~cm}$ with positive resection margin, ileocecal resection was performed. No tumour remains in this specimen was found. One patient with a tumour larger than $2 \mathrm{~cm}$ with angioinvasive growth underwent right hemicolectomy. This specimen was also without residual tumour on pathology. In the other patient with a tumour larger than $2 \mathrm{~cm}$, ileocecal resection was performed. The patient with the goblet-type tumour underwent also ileocecal resection with no evidence of residual tumour in the specimen. Goblet-cell carcinoids have a worse outcome than the other types of carcinoid tumours and frequently present with metastatic disease. ${ }^{4,10,11}$ This patient with a follow-up of 75 months had no recurrence of disease. Lymph from the appendix drains into the retrocecal glands, iloecolic glands, along the iloecolic artery and, finally, to central glands at the base of the superior mestenteric artery. This knowledge gives sense to ileocecectomy for carcionoid of the appendix resecting also the ileocecal artery at its origin from the superior mesenteric artery. At least, it is worth mentioning that patients with carcinoid lesions have a notable risk of developing a synchronous or metachronous colorectal 
neoplasm up to $33 \% .^{1,2,4,12}$ Although none of our patients yet developed a colorectal tumour, follow-up by colonoscopy should be recommended.

From this database, it is concluded that long-term prognosis of incidentally found carcinoids of the appendix is good. It also emphasises the value of histopathological analysis of the removed appendix. Instead of right hemicolectomy, ileocecal resection seems to be the logical operation for tumours larger than $2 \mathrm{~cm}$.

Open Access This article is distributed under the terms of the Creative Commons Attribution Noncommercial License which permits any noncommercial use, distribution, and reproduction in any medium, provided the original author(s) and source are credited.

\section{References}

1. Conner SJ, Hanna GB, Frizelle FA. Appendiceal tumors: retrospective clinicopathologic analysis of appendiceal tumors from 7970 appendectomies. Dis Colon Rectum 1998;410:75-80.

2. Moertel CG, Dockerty MB, Judd ES. Carcinoid tumors of the vermiform appendix. Cancer 1968;21:270-278.
3. Moertel CG, Weiland LH, Nagorney DM, Dockerty MB. Carcinoid tumor of the appendix: treatment and prognosis. $\mathrm{N}$ Eng J Med 1987;317:1699-1701.

4. Goede AC, Caplin ME, Winslet MC. Carcinoid tumour of the appendix. Br J Surg 2003;90:1317-1322.

5. Tchana-Sato V, Detry O, Detroz B, Maweja S, Hamoir E, Defechereux T, Coimbra C, De Roover A, Meurisse M, Honore P. Carcinoid tumour of the appendix: a consecutive series from 1237 appendectomies. World J Gastroenterol 2006;12(41):66996701.

6. Safioleas MC, Moulakakis KG, Kontzoglou K, Stamoulis J, Nikou GC, Toubanakis C, Lygidakis NJ. Carcinoid tumors of the appendix. Prognostic factors and evaluation of indications for right hemicolectomy. Hepatogastroenterology 2005;52(61): 123-127.

7. Mc Cusker ME, Cote TR, Clegg LX, Sobin LH. Primary malignant neoplasma of the appendix; a population based study from the surveillance, epidemiology and end-results program, 1973-1998. Cancer 2002;94:3307-3312.

8. Sandor A, Modlin IM. A retrospective analysis of 1570 appendiceal carcinoids. Am J Gastroenterol 1998;93:422-428.

9. MacGillivray DC, Heaton RB, Rushin JM, Cruess DF. Distant metastasis from a carcinoid tumor of the appendix less than one centimetre in size. Surgery 1992;111:466-471.

10. Butler JA, Houshiar A, Lin F, Wilson SE. Goblet cell carcinoid of the appendix. Am J Surg 1994;168:685-687.

11. Toumpanakis C, Standish RA, Baishnab E, Winslet MC, Caplin ME. Goblet cell carcinoid tumors (adenocarcinoid) of the appendix. Dis Colon Rectum 2007;50(3):315-322.

12. Modlin IM, Lye KD, Kidd M. A 5-decade analysis of 13715 carcinoid tumors. Cancer 2003;97:934-959. 